\title{
Hydrothermal Synthesis of Co-Ru Alloy Particle Catalysts for Hydrogen Generation from Sodium Borohydride
}

\author{
Marija Kurtinaitienė, Albina Žielienė, Loreta Tamašauskaitė-Tamašiūnaitè, \\ Algis Selskis, and Arūnas Jagminas
}

\begin{abstract}
State Research Institute Center for Physical Sciences and Technology, Institute of Chemistry, A. Gostauto 9, 01108 Vilnius, Lithuania
\end{abstract}

Correspondence should be addressed to Arūnas Jagminas; jagmin@ktl.mii.lt

Received 14 May 2013; Accepted 6 September 2013

Academic Editor: Hai Lu

Copyright (C) 2013 Marija Kurtinaitiene et al. This is an open access article distributed under the Creative Commons Attribution License, which permits unrestricted use, distribution, and reproduction in any medium, provided the original work is properly cited.

\begin{abstract}
We report the synthesis of $\mu \mathrm{m}$ and sub- $\mu \mathrm{m}$-sized $\mathrm{Co}, \mathrm{Ru}$, and $\mathrm{Co}-\mathrm{Ru}$ alloy species by hydrothermal approach in the aqueous alkaline solutions $\left(\mathrm{pH} \geq 13\right.$ ) containing $\mathrm{CoCl}_{2}$ and/or $\mathrm{RuCl}_{3}$, sodium citrate, and hydrazine hydrate and a study of their catalytic properties for hydrogen generation by hydrolysis of sodium borohydride solution. This way provides a simple platform for fabrication of the ball-shaped Co-Ru alloy catalysts containing up to $12 \mathrm{wt} \% \mathrm{Ru}$. Note that bimetallic Co- $\mathrm{Ru}$ alloy bowls containing even 7 at.\% $\mathrm{Ru}$ have demonstrated catalytic properties that are comparable with the ones of pure Ru particles fabricated by the same method. This result is of great importance in view of the preparation of cost-efficient catalysts for hydrogen generation from borohydrides. The morphology and composition of fabricated catalyst particles have been characterized using scanning electron microscopy, energy dispersive X-ray diffraction, and inductively coupled plasma optical emission spectrometry.
\end{abstract}

\section{Introduction}

It is commonly accepted that borohydrides, due to high hydrogen density and low toxicity, are among the best hydrogen gas sources and storage containers. Note that hydrogen generation from sodium borohydride theoretically can attain $21.3 \mathrm{wt} \%$ if the by-product (water) is recycled for further hydrolysis. Furthermore, only pure $\mathrm{H}_{2}$ gas and some water vapor are produced in the product gas stream through a chemical reaction of $\mathrm{NaBH}_{4}$ or $\mathrm{NH}_{4} \mathrm{BH}_{4}$ with water according to an equation as follows:

$$
\mathrm{NaBH}_{4}+(2+x) \mathrm{H}_{2} \mathrm{O} \longrightarrow 4 \mathrm{H}_{2}+\mathrm{NaBO}_{2} \cdot x \mathrm{H}_{2} \mathrm{O}+\mathrm{Q}
$$

Under SATP conditions only a small amount of hydrogen, depending on $\mathrm{pH}$, is liberated from aqueous borohydride solutions $[1,2]$. The generation rate, however, can be significantly increased if a suitable catalyst is applied [3,4].

The first report on the hydrogen generation from borohydrides by hydrolysis and the accelerating effect of acids on the $\mathrm{H}_{2}$ gas yield has been presented in the early 1950s [5]. A high efficiency of bulk ruthenium catalysts for hydrogen pro- duction from borohydrides has been reported in several works [6-9]. As already referred, except for the transition metals and $\mathrm{Ru}$, other precious metals such as $\mathrm{Rh}, \mathrm{Pd}$, and $\mathrm{Pt}$ and various metal oxides such as $\mathrm{CoO}, \mathrm{Co}_{3} \mathrm{O}_{4}, \mathrm{TiO}_{2}, \mathrm{SiO}_{2}$, $\mathrm{NiO}, \mathrm{LiNiO}_{3}$, and $\mathrm{LiCoO}_{2}$ can be successfully applied to catalyze the reaction (1) [10-13]. It has also been reported that decrease in the size of catalyst species results in the enhancement of hydrogen gas evolution rate [10], as it is typical for heterogeneous catalysis. By this way, Ru nanoparticles supported onto graphite [14] or a finely grained Ni catalysts [15] resulted in an exciting hydrogen generation rate increase. To date, various synthesis protocols have also been reported for fabrication of three-dimensional (3D) Co assembles composed of subunits such as nm-sized Co chains and Co submicrospheres [16], Co nanoflowers, and nanorods [17], Co microspheres [18], and nanoflakes [19-22]. However, most of these hierarchical architectures have been created seeking to improve magnetic properties of nanostructured cobalt layers. The application of these materials for catalytic generation of hydrogen gas from borohydrides has not been reported yet. There are also no reports on the catalytic behavior of various 
Co-Ru alloy species as catalysts for hydrogen generation from borohydrides. On the other hand, it is reasonable to suspect that bimetallic particles, possessing unique physical and chemical properties, allow them to be explored for efficient hydrogen generation. Therefore, the purpose of this study was to develop the synthesis protocols of $\mathrm{Co}, \mathrm{Ru}$, and Co-Ru bimetallic particles by a hydrothermal approach and to evaluate their efficiency as catalysts for sodium borohydride hydrolysis. In fact, the hydrothermal synthesis protocols of Co-Ru alloy submicrospheres, their morphology, and catalytic properties for hydrogen generation from borohydrides are explored here for the first time.

\section{Experiments}

All of the chemical reagents were of analytic grade purchased from Sigma-Aldrich and used without further purification. In a typical experimental procedure, $1.6 \mathrm{mmol} \mathrm{CoCl} \cdot 6 \mathrm{H}_{2} \mathrm{O}$, $3.2 \mathrm{mmol} \mathrm{Na}$ citrate, and from 0 to $0.48 \mathrm{mmol} \mathrm{RuCl}_{3}$ were dissolved in $30 \mathrm{~mL}$ distilled water. Following further addition of 1.0 to $3.0 \mathrm{~mL}$ of $\mathrm{NaOH}(5.0 \mathrm{M})$ solution and $4.8 \mathrm{~mL}$ of hydrazine hydrate $(50 \%)$ and water up to the total volume of $40 \mathrm{~mL}$, an alkaline solution containing $40 \mathrm{mmol} / \mathrm{L}$ of $\mathrm{Co}^{2+}$ ions with $\mathrm{pH} \geq 13$ was obtained and sealed into an $80 \mathrm{~mL}$ Teflon-lined autoclave. The hydrothermal treatment was conducted at $120^{\circ} \mathrm{C}$, using $10^{\circ} \mathrm{C} / \mathrm{min}$ ramp, for $10 \mathrm{~h}$. The autoclave was then cooled to room temperature naturally. The products were harvested by centrifugation, thoroughly washed several times using distilled water and ethanol, and finally dried in an oven at $60^{\circ} \mathrm{C}$. A similar procedure was performed following the synthesis of pure $\mathrm{Ru}$ species. In this case, a solution containing $40 \mathrm{mmol} / \mathrm{L} \mathrm{RuCl}_{3}, 80 \mathrm{mmol} / \mathrm{L} \mathrm{Na}$ citrate, $0.125 \mathrm{~mol} / \mathrm{L}$ $\mathrm{NaOH}$, and $0.12 \mathrm{~mol} / \mathrm{L}$ hydrazine hydrate was explored under the same hydrothermal conditions.

The composition of Co-Ru nanoalloys was studied directly by energy dispersive X-ray spectroscopy (EDX) and following dissolution of some quantity of synthesized products in a hot $\mathrm{HNO}_{3}-\mathrm{HCl}(1: 3)$ solution by inductively coupled plasma optical emission spectrometry analysis.

The catalytic reactivity of synthesized $\mathrm{Co}, \mathrm{Ru}$, and Co-Ru alloy particles was determined by measuring the amount of hydrogen gas that evolved from the hydrolysis of sodium borohydride. To prevent self-hydrolysis, aqueous solutions containing $0.4 \% \mathrm{NaBH}_{4}$ were stabilized by addition of $0.25 \mathrm{~mol} / \mathrm{L}$ $\mathrm{NaOH}$. In each experiment, a freshly prepared solution (5.0 $\mathrm{mL}$ ) was placed into a thermostated Erlenmeyer flash with the catalyst powder $(5 \mathrm{mg})$ and sealed. The amount of generated hydrogen was determined with a volumetric burette in a gas analyzer every $2-5 \mathrm{~min}$ of processing.

Images of the particles were taken on a field emission scanning electron microscope (FESEM) model Hitachi S-6000. Samples were prepared by drying solvent dispersions of the nanoparticles onto the Formvar amorphous carbonbacked 200 mesh grid. X-ray powder diffraction experiments were performed on a D8 diffractometer (Bruker AXS, Germany), equipped with a Göbel mirror as a primary beam monochromator for $\mathrm{CuK}_{\alpha}$ radiation.
The results are presented as the mean value of triplicate samples unless otherwise stated.

\section{Results and Discussion}

To generate the particles of $\mathrm{Co}, \mathrm{Ru}$, and various solid $\mathrm{Ru}$ solutions in Co we have used here degassed alkaline solutions composed of $\mathrm{CoCl}_{2}$ and $\mathrm{RuCl}_{3}$ precursors, $\mathrm{NaOH}$, and hydrazine hydrate as a reducing agent. The complexation of these solutions was carried out through the addition of sodium citrate and $\mathrm{NaOH}$ up to $\mathrm{pH} \geq 13.0$. It is noteworthy that in aqueous solutions the reduction potential of $\mathrm{Co}$ (II) species $(-0.28 \mathrm{~V})$ differs from $\mathrm{Ru}(\mathrm{III})(+0.68 \mathrm{~V})$ significantly. Thence, the simultaneous reduction of cobalt and ruthenium species, possessing different reduction potentials, is somehow problematic. To overcome this, a strong reducer, particularly $\mathrm{H}_{4} \mathrm{~N}_{2} \cdot x \mathrm{H}_{2} \mathrm{O}$, and hydrothermal approach were applied in this study. We note that hydrothermal synthesis is a powerful tool embraces the chemical, thermal, and pressure induced driving forces allowing the formation of bimetallic crystalline materials from various precursors under appropriate treatment conditions [23].

Typical morphologies of the $\mathrm{Co}, \mathrm{Ru}$, and Co-Ru alloy products obtained under the optimized autoclaving conditions $\left(120^{\circ} \mathrm{C}, 10 \mathrm{~h}, 10^{\circ} \mathrm{C} / \mathrm{min}\right)$ are presented in Figure 1 . As seen, fern-like cobalt species composed of numerous leaflets of up to several microns in length are formed in the solution without the ruthenium precursor (Figure 1(a)). Both the shape of metallic $\mathrm{Co}^{0}$ species and sub- $\mu \mathrm{M}$ thickness of leaflets imply a huge surface area. The shape and size of pure $\mathrm{Ru}^{0}$ species grown under the same autoclaving conditions differ significantly (Figure 1(b)). In this case, both separate spherical crystals of submicrometer size and the tangled ones forming spherical aggregates are formed. The morphology of bimetallic $\mathrm{Co}-\mathrm{Ru}$ products produced by the same way was studied herein varying the concentrations ratio, $\left[\mathrm{Co}^{2+} / \mathrm{Ru}^{3+}\right]$, from $10: 0.25$ to $10: 2$ and the reaction temperature within the $[110-150]^{\circ} \mathrm{C}$ range. In this way, we have found that increasing in $\left[\mathrm{Ru}^{3+}\right]$ concentration results in the formation of $\mathrm{Co}-\mathrm{Ru}$ species with a higher content of ruthenium attaining $12 \mathrm{wt} \%$. Note that in most synthesis cases, the products obtained are bowl-shaped differing in size and dispersion of their diameters (Figure 1(c)). Besides, the surface of Co-Ru alloy bowls is not smooth and looks trenched (Figure $1(\mathrm{~d})$ ). It is also seen that some parts of Co-Ru dumplings, differing in size, are combined together implying that the growth of these crystallites proceeds via "oriented attachment" pathway by which nanoparticles with common crystallographic orientations combine [24].

To determine if Co-Ru particles could be generated in the same alkaline $\mathrm{Co}$ (II) and $\mathrm{Ru}$ (III) precursor solutions with sodium citrate at ambient pressure, control experiments at $20^{\circ}, 40^{\circ}$, and $70^{\circ} \mathrm{C}$ were conducted. By this way, it was found that the reduction of cobalt and ruthenium species at room temperature proceeds exceptionally at a low rate without the formation of alloyed nanoparticles even during several days, while, at $40^{\circ} \mathrm{C}, \mathrm{Co}-\mathrm{Ru}$ alloy coats the glass-reactor walls just after several minutes (Figure 2(a)). The detailed observations 


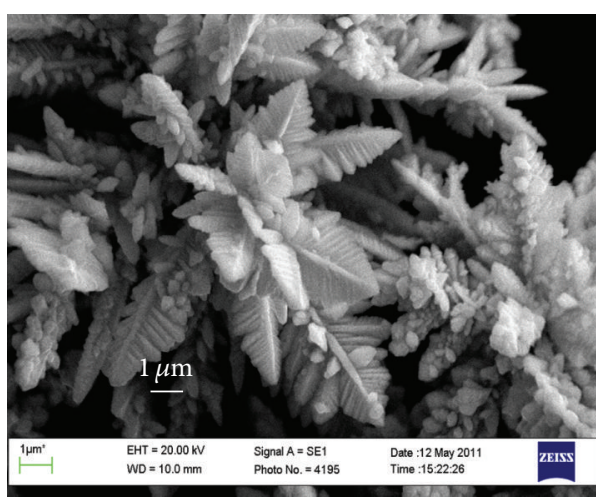

(a)

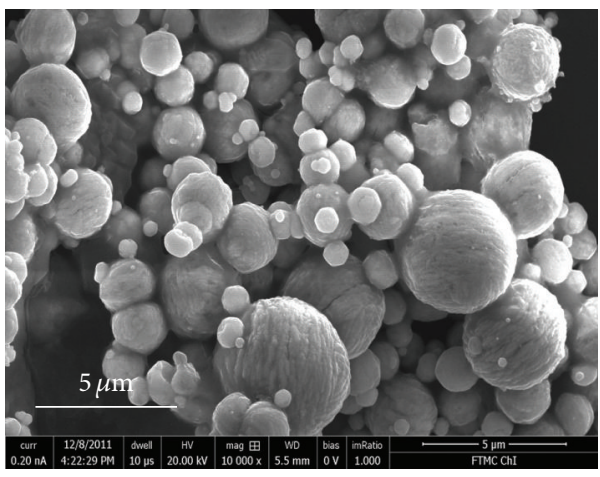

(c)

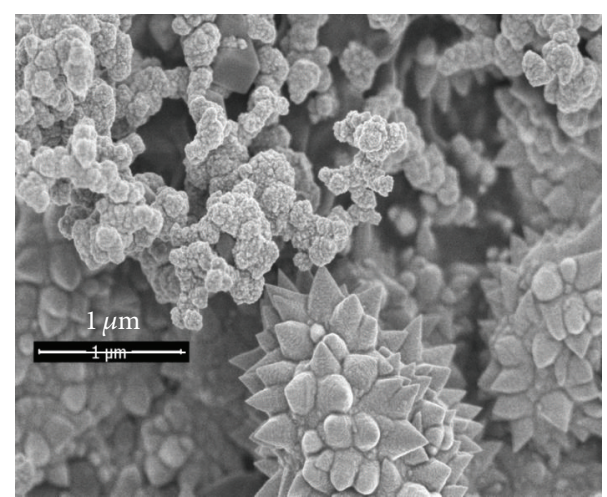

(b)

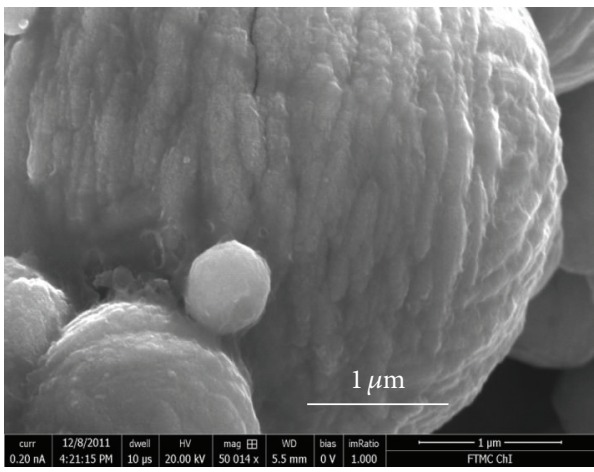

(d)

FIgURE 1: FESEM views of synthesized Co (a), Ru (b), and Co-Ru ((c), (d)) products by a hydrothermal way at $120^{\circ} \mathrm{C}$ for $10 \mathrm{~h}$. The solution containing $0.04 \mathrm{CoCl}_{2}, 0.004 \mathrm{RuCl}_{3}, 0.08$ sodium citrate, $0.33 \mathrm{NaOH}$, and $1.7 \mathrm{~mol} / \mathrm{L}$ hydrazine hydrate was explored for Co-Ru fabrication, while for pure $\mathrm{Co}$ and $\mathrm{Ru}$ species, only their precursors at $0.04 \mathrm{~mol} / \mathrm{L}$ and the same additives as for Co-Ru synthesis were used.

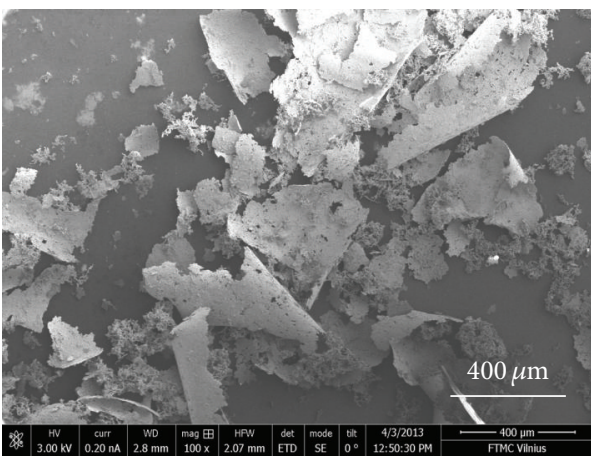

(a)

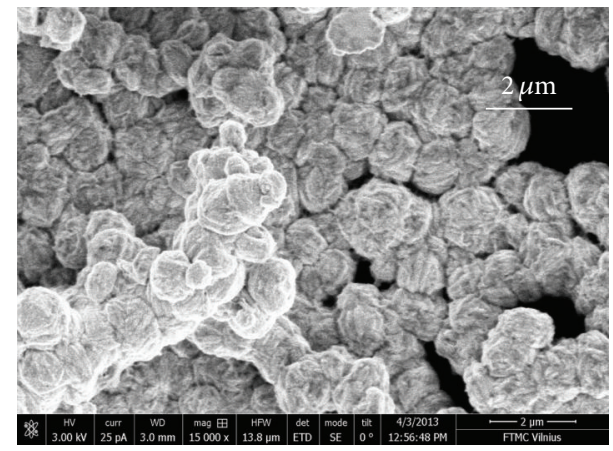

(b)

Figure 2: SEM views of Co-Ru alloy product formed in an aqueous solution of $0.04 \mathrm{CoCl}_{2}, 0.004 \mathrm{RuCl}_{3}, 0.08$ sodium citrate, $0.33 \mathrm{NaOH}$, and $1.7 \mathrm{~mol} / \mathrm{L}$ hydrazine hydrate at ambient pressure and $40^{\circ} \mathrm{C}$ for $5 \mathrm{~min}$.

revealed that these films are composed of numerous micrometer-sized particles of Co-Ru alloy (Figure 2(b)). However, only 30 to $43 \%$ of ruthenium species were reduced under these conditions. Besides, the increase in the reaction temperature up to $70^{\circ} \mathrm{C}$ results into extremely intensive evolution of $\mathrm{NH}_{3}$ gas and uncontrollable reaction directed to the formation of film material.

The XRD pattern (Figure 3(a)) of the Co-Ru alloy particles, obtained by autoclaving under conditions of this study and containing up to $7 \mathrm{wt} \%$ of ruthenium, comprises six peaks at $2 \Theta=41.15^{\circ}, 44.34^{\circ}, 46.88^{\circ}, 61.80^{\circ}, 75.03^{\circ}$, and $83.28^{\circ}$ attributable to the hexagonal close-packed ( $h c p)$ space group p63/mmc(194) of crystalline cobalt (PDF 01-071-4652) peaked at $2 \Theta=41.44^{\circ}, 44.08^{\circ}, 47.22^{\circ}, 62.10^{\circ}, 75.58^{\circ}$, and $83.35^{\circ}$. A certain shift in experimental diffraction lines towards lower diffraction angles ought to be attributed to the formation of a solid solution of $\mathrm{Ru}$ in Co distorting the crystalline lattices of Co. The XRD pattern of Co-Ru alloy particles, containing 


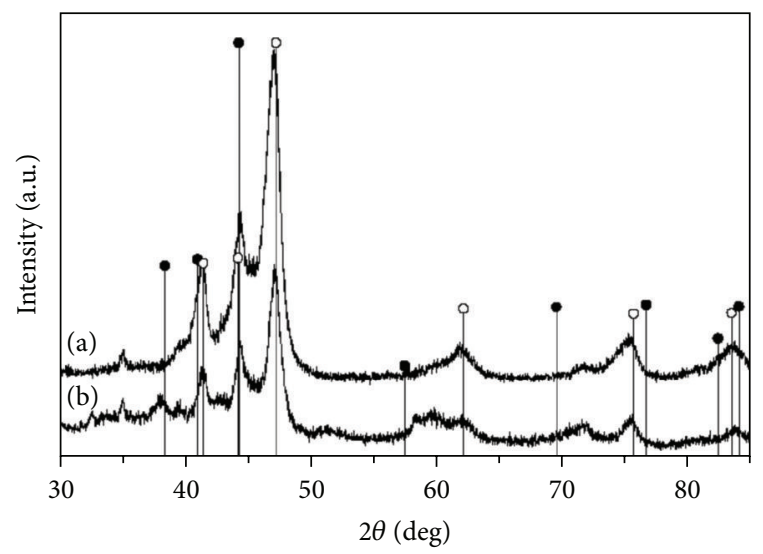

- $\mathrm{Ru}(\mathrm{PDF}$ 04-001-0053)

○ Co (PDF 01-071-4652)

FIGURE 3: XRD patterns of species fabricated by hydrothermal route $\left(120^{\circ} \mathrm{C}, 10 \mathrm{~h}\right)$ in the solutions containing $40 \mathrm{mmol} / \mathrm{L} \mathrm{CoCl}_{2}$ $80 \mathrm{mmol} / \mathrm{L}$ sodium citrate, $0.33 \mathrm{~mol} / \mathrm{L} \mathrm{NaOH}, 108 \mathrm{~mL} / \mathrm{L}$ hydrazine hydrate (50\%), and $\mathrm{RuCl}_{3}$ (mmol/L): (a) 2.5; (b) 5.0 .

more $\mathrm{Ru}$, is more complex (Figure 3(b)). Except the main diffraction peaks assigned to Co alloy, there are some weak additional peaks and shoulders, for example, at $2 \Theta$ diffraction angles $35.01^{\circ}$ and $71.53^{\circ}$. We suspect that in this case other finely grained crystalline phases in the solid solution of $\mathrm{Ru}$ in $\mathrm{Co}$, such as $\mathrm{Co}\left(\mathrm{Co}_{1.108} \mathrm{Ru}_{0.892}\right) \mathrm{O}_{4}$ indicated in PDF card no. 01-089-8629, could be formed.

As in the following, the hydrolysis of $\mathrm{NaBH}_{4}$ solution was investigated by using synthesized $\mathrm{Co}, \mathrm{Ru}$, and $\mathrm{Co}-\mathrm{Ru}$ alloy particles as catalysts. The plot in Figure 4 shows hydrogen production profiles for hydrolysis reaction (1) in a $5 \mathrm{~mL}$ solution containing $0.1 \mathrm{NaBH}_{4}+0.25 \mathrm{~mol} / \mathrm{L} \mathrm{NaOH}+5.0 \mathrm{mg}$ of catalyst powder at a temperature of $30^{\circ} \mathrm{C}$ versus the processing time. It is seen that the highest hydrogen gas generation rate, approximated as $1.3 \mathrm{~L}\left(\mathrm{H}_{2}\right) / \mathrm{min} \cdot \mathrm{g}$, is characteristic for pure $\mathrm{Ru}^{0}$ species, while under the same hydrolysis conditions the application of pure cobalt species gives only 0.18 $\mathrm{L}\left(\mathrm{H}_{2}\right) / \mathrm{min} \cdot \mathrm{g}$ yield. A quite high hydrogen generation rate for synthesized dendritically shaped Co species probably could be linked with a large surface area of this catalyst. From the numerous experimental results carried out in this study, the amount of evolved hydrogen under otherwise identical conditions was found to be dependent on the content of ruthenium in the catalysts increasing drastically with the $\mathrm{Ru}$ interposition. The effect of ruthenium content in the Co-Ru alloy on the hydrogen generation efficiency is obvious from the plot of the time spent for hydrolysis of half the amount of $\mathrm{NaBH}_{4}\left(t_{1 / 2 \mathrm{H}}\right)$ presented in Figure 5. As seen, when $5 \mathrm{mg}$ of the Co-Ru bowls containing only 7 at $\%$ of $\mathrm{Ru}$ was used as catalyst (inset in Figure 5) $t_{1 / 2 \mathrm{H}}$ approximated $\leq 3$ min which is close to the time of hydrolysis of the same amount of $\mathrm{NaBH}_{4}$ onto the pure $5 \mathrm{mg} \mathrm{Ru}$ catalyst (about $2 \mathrm{~min}$ ), shown by a dashed line in Figure 5. These findings indicate that bimetallic Co-Ru sub- $\mu \mathrm{M}$-sized bowls, synthesized by hydrothermal approach and containing only $5-7$ at $\%$ of $\mathrm{Ru}$, possess high catalytic activity and can be undoubtedly useful catalysts for the generation of hydrogen gas from borohydrides.

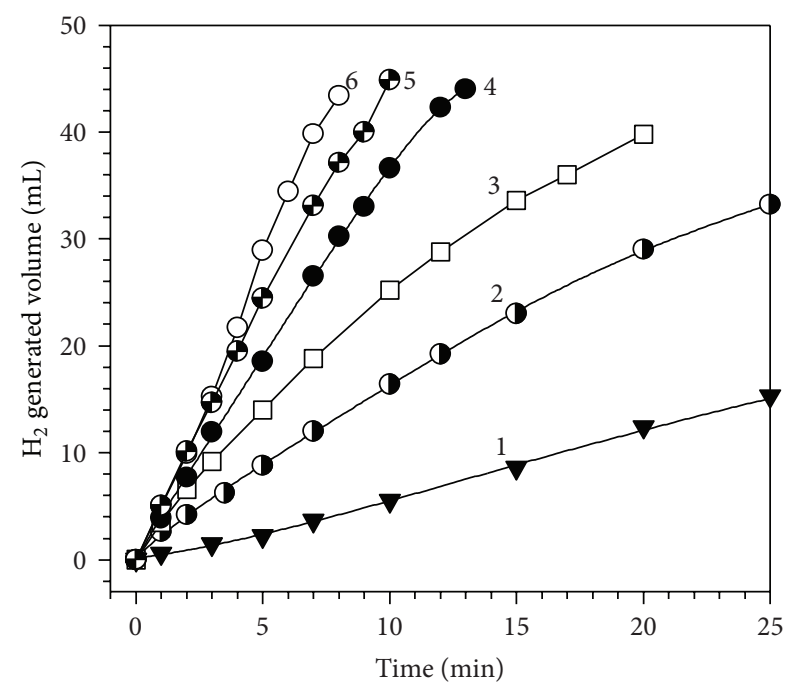

FigURE 4: Volume of hydrogen generated from $5 \mathrm{~mL}$ of $0.1 \mathrm{NaBH}_{4}+$ $0.33 \mathrm{~mol} / \mathrm{L} \mathrm{NaOH}$ solution at $30^{\circ} \mathrm{C}$ as a function of processing time for synthesized $\mathrm{Co}(1), \mathrm{Ru}(6)$, and Co-Ru alloy catalysts containing 2.6 (2), 3.8 (3), 5.7 (4), 7.1 (5), and 11.1 (6) at\% Ru each in 5 mg.

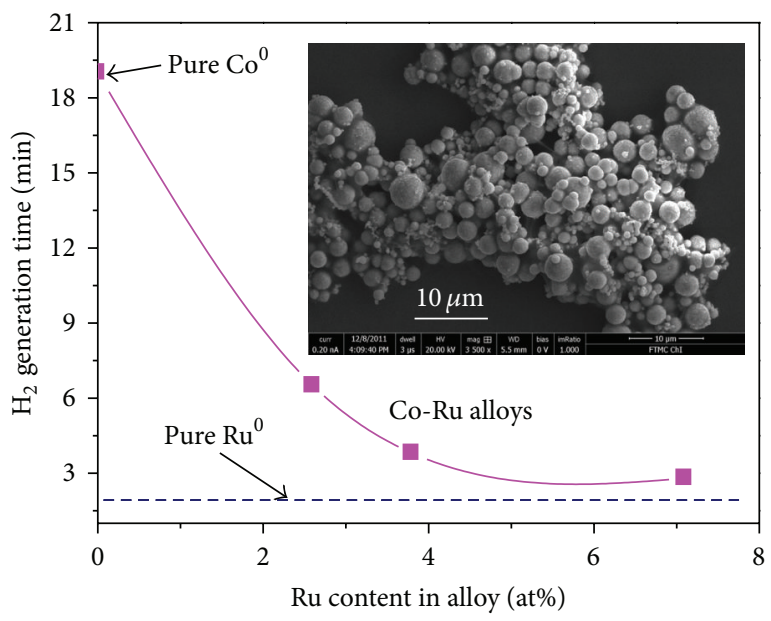

FIgURE 5: Variation of the time consumed for generation of half amount of $\mathrm{H}_{2}$ gas from that theoretically calculated $(47.4 \mathrm{~mL})$ when $0.4 \% \mathrm{NaBH}_{4}$ solution $(5 \mathrm{~mL})$ was explored using $5 \mathrm{mg}$ of pure $\mathrm{Ru}^{0}$ (dashed line), pure $\mathrm{Co}$, and $\mathrm{Co}-\mathrm{Ru}$ alloy catalysts at $30^{\circ} \mathrm{C}$. Inset depicts an FESEM view of alloy microspheres.

In this study, to determine the activation energy of $\mathrm{NaBH}_{4}$ hydrolysis reaction on the Co- $\mathrm{Ru}$ alloy catalysts, $\mathrm{H}_{2}$ generation rates were studied within the 20 to $60^{\circ} \mathrm{C}$ temperature range employing $5 \mathrm{~mL}$ of $0.1 \mathrm{NaBH}_{4}+0.25 \mathrm{~mol} / \mathrm{L} \mathrm{NaOH}$ solution and $5 \mathrm{mg}$ of powdered catalyst. The obtained kinetic plots for Co-Ru alloy (3.8 at\% Ru) are presented in Figure 6(a). As seen, the increase in solution temperature results in increasing the rate of $\mathrm{H}_{2}$ evolution. The hydrogen evolution rates determined at various processing temperatures were further 


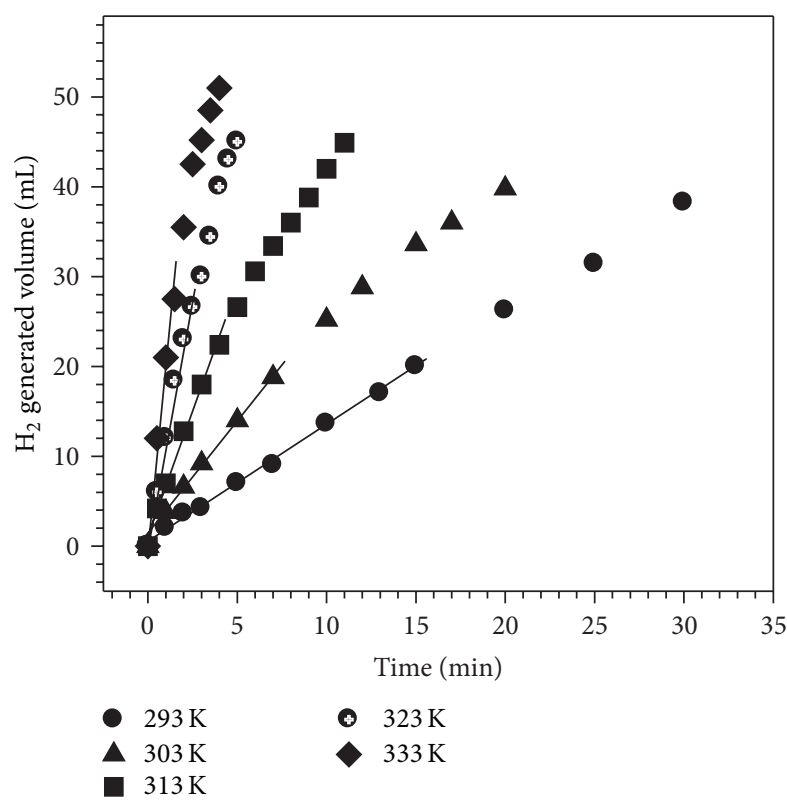

(a)

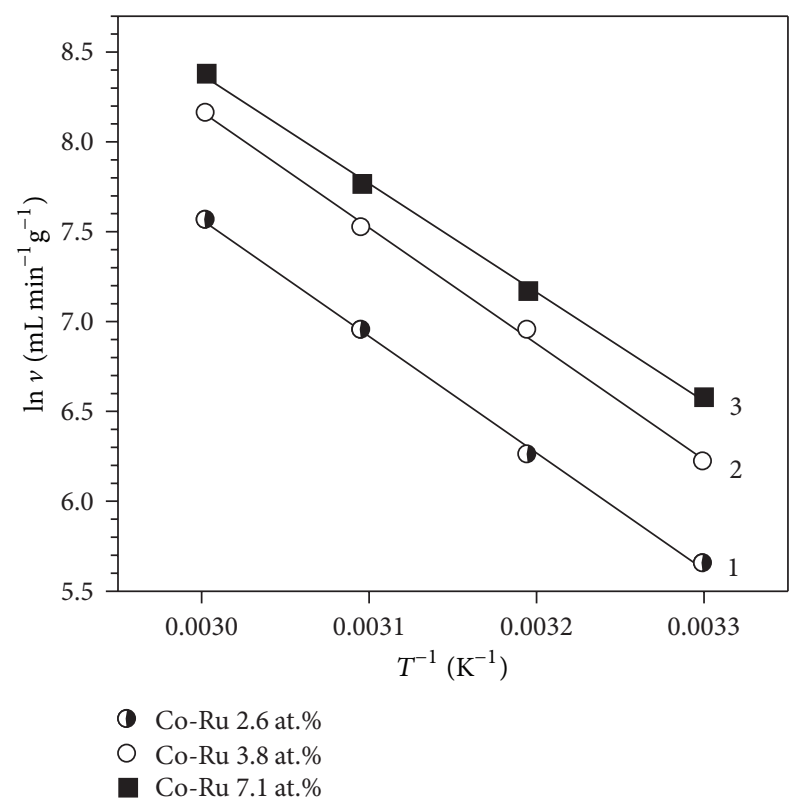

(b)

Figure 6: (a) Hydrogen generation kinetic plots of the $0.1 \mathrm{NaBH}_{4}+0.25 \mathrm{~mol} / \mathrm{L} \mathrm{NaOH}$ solution employing the Co- $\mathrm{Ru}$ (3.8 at\%) catalyst $(5 \mathrm{mg})$ at indicated temperatures. (b) The Arrhenius plots calculated from $\mathrm{NaBH}_{4}$ hydrolysis rates in the same solution for various $\mathrm{Co}-\mathrm{Ru}$ alloy catalysts.

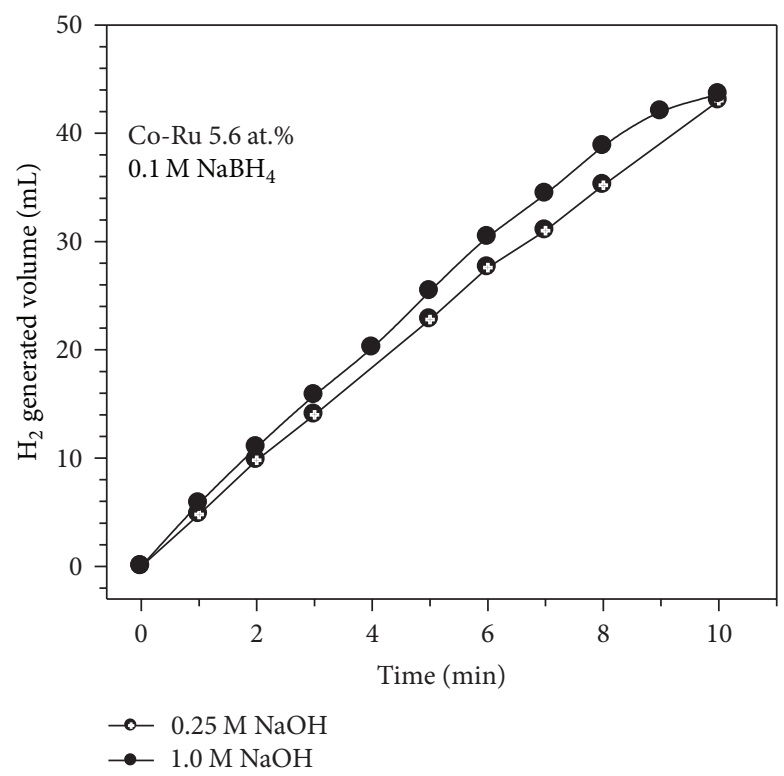

(a)

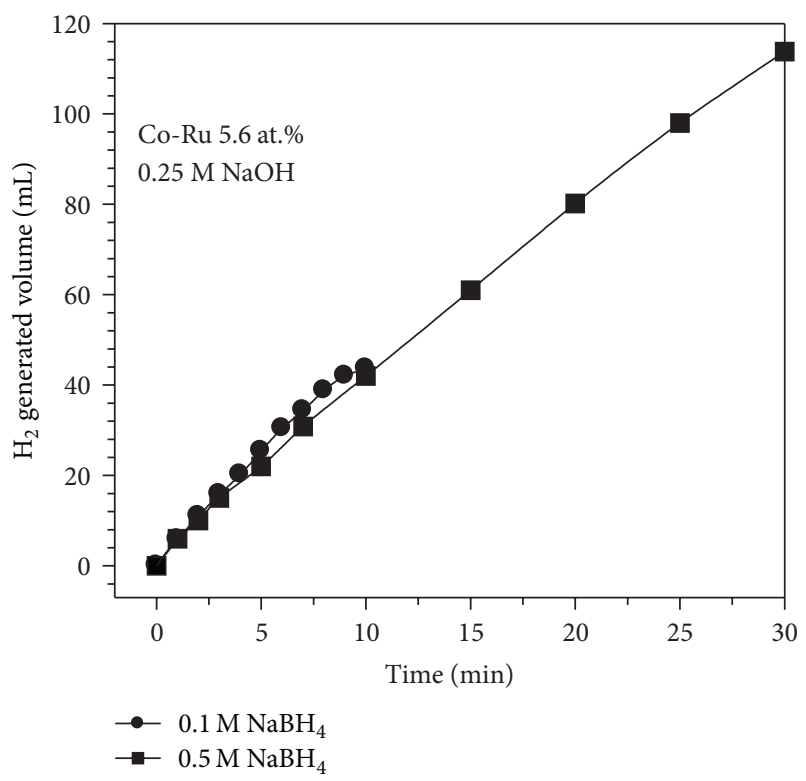

(b)

FIGURE 7: Volume of hydrogen generated as a function of time and the composition of solution applied for the Co-Ru (3.8 at\%) catalyst.

applied to calculate the activation energy of various $\mathrm{Co}-\mathrm{Ru}$ alloys according to the following relation:

$$
v=k_{0} \exp \left(-\frac{E_{a}}{R T}\right)
$$

where $v$ is the reaction rate in $\mathrm{mL} / \mathrm{min} \cdot \mathrm{g}, k_{0}$ is the reaction constant in $\mathrm{mL} / \mathrm{min} \cdot \mathrm{g}, E_{a}$ is the activation energy of the reaction (1) in $\mathrm{kJ} / \mathrm{mol}, R$ is the gas constant $(8.314 \mathrm{~kJ} / \mathrm{mol} \cdot \mathrm{K})$, and $T$ is the reaction temperature in $\mathrm{K}$. The calculated Arrhenius plots, for example, $\ln v$ versus $1 / T$, for catalysts containing from 2.6 to 7.12 at\% of Ru are shown in Figure 6(b). From the slopes of straight lines, the activation energy was approximated to be $53.5,54.31$ and $50.41 \mathrm{~kJ} / \mathrm{mol}$ for Co-Ru microbowl catalysts containing $2.6,3.8$, and $7.1 \mathrm{at} \%$ of $\mathrm{Ru}$, 
respectively, which are higher than those of pure ruthenium nanoclusters (42 kJ/mol) [25] but significantly lower than those of bulk metallic Co (75 kJ/mol) [26].

It was reported that the concentration of $\mathrm{NaOH}$ can affect the rate of catalytic hydrolysis of $\mathrm{NaBH}_{4}$ : namely, inhibition characteristic of noble metal catalysts $[8,14,27]$ and acceleration characteristic of transition metal catalysts [28-30]. The influence of $\mathrm{NaOH}$ concentration on $\mathrm{H}_{2}$ generation rate for the Co-Ru alloy microsphere catalyst, fabricated in this study, is shown in Figure 7(a) which demonstrates a slight accelerating effect of $\left[\mathrm{OH}^{-}\right]$within at least a particular concentration range. However, variations in the concentration of $\mathrm{NaBH}_{4}$ do not have a significant influence on the $\mathrm{BH}_{4}^{-}$hydrolysis rate from the alkaline solution (Figure $7(\mathrm{~b})$ ), as in some other catalysts application cases $[4,31,32]$.

\section{Conclusions}

In this work, for the synthesis of nanostructured Co-Ru alloy catalysts containing from several to 11 at $\%$ of $\mathrm{Ru}$, an environmentally benign hydrothermal process in alkaline $\mathrm{Co}(\mathrm{II})$ and $\mathrm{Ru}$ (III) chloride solutions containing sodium citrate, $\mathrm{NaOH}$ and hydrazine hydrate has been suggested. Surprisingly, Co and Co-Ru alloy species of quite different structures have been obtained by this method under the same synthesis conditions without and with a $\mathrm{RuCl}_{3}$ precursor. The addition of $\mathrm{RuCl}_{3}$ to the reaction solution even in low concentrations results in the formation of bowl-shaped Co-Ru alloy particles instead of fern-like pure Co species traditionally formed without $\mathrm{RuCl}_{3}$. It was also demonstrated that these Co- $\mathrm{Ru}$ bowls are effective catalysts for hydrogen generation from the alkaline solution of sodium borohydride. Note that hydrogen generation rates onto the Co-Ru alloy species containing only 5-7 at\% of Ru are comparable to those obtained using pure Ru particles synthesized by the same approach.

\section{Acknowledgments}

The support of this work by the Lithuania Science Foundation under Grant no. ATE-08/2012 is gratefully acknowledged. The authors are grateful to Dr. V. Pakštas for help with XRD characterization.

\section{References}

[1] V. C. Y. Kong, F. R. Foulkes, D. W. Kirk, and J. T. Hinatsu, “Development of hydrogen storage for fuel cell generators. I: hydrogen generation using hydrolysis hydrides," International Journal of Hydrogen Energy, vol. 24, no. 7, pp. 665-675, 1999.

[2] R. Aiello, J. H. Sharp, and M. A. Matthews, "Production of hydrogen from chemical hydrides via hydrolysis with steam," International Journal of Hydrogen Energy, vol. 24, no. 12, pp. 1123-1130, 1999.

[3] U. B. Demirci and F. Garin, "Ru-based bimetallic alloys for hydrogen generation by hydrolysis of sodium tetrahydroborate," Journal of Alloys and Compounds, vol. 463, no. 1-2, pp. 107111, 2008.
[4] B. H. Liu and Z. P. Li, "A review: hydrogen generation from borohydride hydrolysis reaction," Journal of Power Sources, vol. 187, no. 2, pp. 527-534, 2009.

[5] H. I. Schlesinger, H. C. Brown, A. E. Finholt, J. R. Gilbreath, H. R. Hoekstra, and E. K. Hyde, "Sodium borohydride, its hydrolysis and its use as a reducing agent and in the generation of hydrogen," Journal of the American Chemical Society, vol. 75, no. 1, pp. 215-219, 1953.

[6] H. C. Brown and C. A. Brown, "New, highly active mental catalysts for the hydrolysis of borohydride," Journal of the American Chemical Society, vol. 84, no. 8, pp. 1493-1494, 1962.

[7] S. C. Amendola, S. L. Sharp-Goldman, M. S. Janjua, M. T. Kelly, P. J. Petillo, and M. Binder, "An ultrasafe hydrogen generator: aqueous, alkaline borohydride solutions and Ru catalyst," Journal of Power Sources, vol. 85, no. 2, pp. 186-189, 2000.

[8] S. C. Amendola, S. L. Sharp-Goldman, M. S. Janjua et al., "Safe, portable, hydrogen gas generator using aqueous borohydride solution and Ru catalyst," International Journal of Hydrogen Energy, vol. 25, no. 10, pp. 969-975, 2000.

[9] D. Gervasio, S. Tasik, and F. Zenhausem, "Room temperature micro-hydrogen-generator," Journal of Power Sources, vol. 149, pp. 15-21, 2005.

[10] Y. Kojima, K.-I. Suzuki, K. Fukumoto et al., "Hydrogen generation using sodium borohydride solution and metal catalyst coated on metal oxide," International Journal of Hydrogen Energy, vol. 27, no. 10, pp. 1029-1034, 2002.

[11] Y. Kojima, K.-I. Suzuki, K. Fukumoto et al., "Development of $10 \mathrm{~kW}$-scale hydrogen generator using chemical hydride," Journal of Power Sources, vol. 125, no. 1, pp. 22-26, 2004.

[12] Q. Xu and M. Chandra, "Catalytic activities of non-noble metals for hydrogen generation from aqueous ammonia-borane at room temperature," Journal of Power Sources, vol. 163, no. 1, pp. 364-370, 2006.

[13] M. Zahmakiran and S. Özkar, "Zeolite-confined ruthenium(0) nanoclusters catalyst: record catalytic activity, reusability, and lifetime in hydrogen generation from the hydrolysis of sodium borohydride," Langmuir, vol. 25, no. 5, pp. 2667-2678, 2009.

[14] Y. Liang, H.-B. Dai, L.-P. Ma, P. Wang, and H.-M. Cheng, "Hydrogen generation from sodium borohydride solution using a ruthenium supported on graphite catalyst," International Journal of Hydrogen Energy, vol. 35, no. 7, pp. 3023-3028, 2010.

[15] M. J. F. Ferreira, L. Gales, V. R. Fernandes, C. M. Rangel, and A. M. F. R. Pinto, "Alkali free hydrolysis of sodium borohydride for hydrogen generation under pressure," International Journal of Hydrogen Energy, vol. 35, no. 18, pp. 9869-9878, 2010.

[16] Y.-J. Zhang, Q. Yao, Y. Zhang et al., "Solvothermal synthesis of magnetic chains self-assembled by flowerlike cobalt submicrospheres," Crystal Growth and Design, vol. 8, no. 9, pp. 3206-3212, 2008.

[17] Q. Liu, X. Guo, Y. Li, and W. Shen, "Hierarchical growth of co nanoflowers composed of nanorods in polyol," Journal of Physical Chemistry C, vol. 113, no. 9, pp. 3436-3441, 2009.

[18] X. ] Yang, Q. W. Chen, and J. Z. Zhang, "Shape-controlled synthesis and self-assembly of hexagonal cobalt ultrathin nanoflakes," Materials Chemistry and Physics, vol. 113, pp. 675-681, 2009.

[19] H. Li, Z. Jin, H. Song, and S. Liao, "Synthesis of Co submicrospheres self-assembled by Co nanosheets via a complexantassisted hydrothermal approach," Journal of Magnetism and Magnetic Materials, vol. 322, no. 1, pp. 30-35, 2010. 
[20] Y. Hou, H. Kondoh, and T. Ohta, "Self-assembly of Co nanoplatelets into spheres: synthesis and characterization," Chemistry of Materials, vol. 17, no. 15, pp. 3994-3996, 2005.

[21] H. Qi, W. Zhang, X. Wang et al., "Heck reaction catalyzed by flower-like cobalt nanostructures," Catalysis Communications, vol. 10, no. 8, pp. 1178-1183, 2009.

[22] R.-H. Wang, J.-S. Jiang, and M. Hu, "Metallic cobalt microcrystals with flowerlike architectures: synthesis, growth mechanism and magnetic properties," Materials Research Bulletin, vol. 44, no. 7, pp. 1468-1473, 2009.

[23] M. Yoshimura and K. Byrappa, "Hydrothermal processing of materials: Past, present and future," Journal of Materials Science, vol. 43 , no. 7, pp. 2085-2103, 2008.

[24] J. Zhang, F. Huang, and Z. Lin, "Progress of nanocrystalline growth kinetics based on oriented attachment," Nanoscale, vol. 2, no. 1, pp. 18-34, 2010.

[25] M. Zahmakiran and S. Özkar, "Water dispersible acetate stabilized ruthenium( $(0)$ nanoclusters as catalyst for hydrogen generation from the hydrolysis of sodium borohyride," Journal of Molecular Catalysts A, vol. 258, pp. 95-103, 2006.

[26] C. M. Kaufman and B. Sen, "Hydrogen generation by hydrolysis of sodium tetrahydroborate: effects of acids and transition metals and their salts," Journal of the Chemical Society, Dalton Transactions, no. 2, pp. 307-313, 1985.

[27] Z. Liu, B. Guo, S. H. Chan, E. H. Tang, and L. Hong, "Pt and Ru dispersed on $\mathrm{LiCoO}_{2}$ for hydrogen generation from sodium borohydride solutions," Journal of Power Sources, vol. 176, no. 1, pp. 306-311, 2008.

[28] D. Hua, Y. Hanxi, A. Xinping, and C. Chuansin, "Hydrogen production from catalytic hydrolysis of sodium borohydride solution using nickel boride catalyst," International Journal of Hydrogen Energy, vol. 28, no. 10, pp. 1095-1100, 2003.

[29] S. U. Jeong, R. K. Kim, E. A. Cho et al., "A study on hydrogen generation from $\mathrm{NaBH}_{4}$ solution using the high-performance Co-B catalyst," Journal of Power Sources, vol. 144, no. 1, pp. 129134, 2005.

[30] J. C. Ingersoll, N. Mani, J. C. Thenmozhiyal, and A. Muthaiah, "Catalytic hydrolysis of sodium borohydride by a novel nickelcobalt-boride catalyst," Journal of Power Sources, vol. 173, no. 1, pp. 450-457, 2007.

[31] Q. Zhang, Y. Wu, X. Sun, and J. Ortega, "Kinetics of catalytic hydrolysis of stabilized sodium borohydride solutions," Industrial and Engineering Chemistry Research, vol. 46, no. 4, pp. 1120-1124, 2007.

[32] Y. Shang and R. Chen, "Semiempirical hydrogen generation model using concentrated sodium borohydride solution," Energy and Fuels, vol. 20, no. 5, pp. 2149-2154, 2006. 

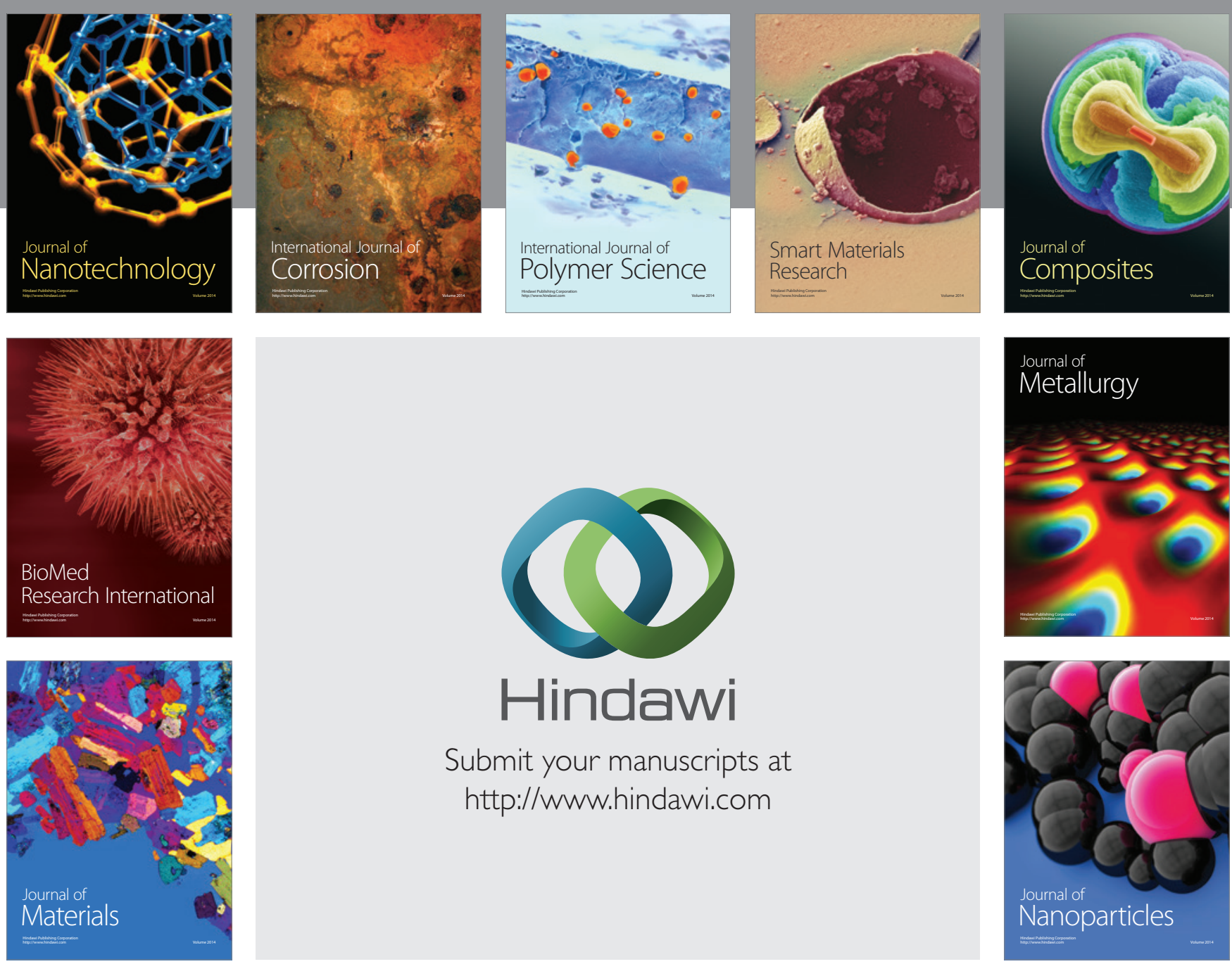

Submit your manuscripts at http://www.hindawi.com
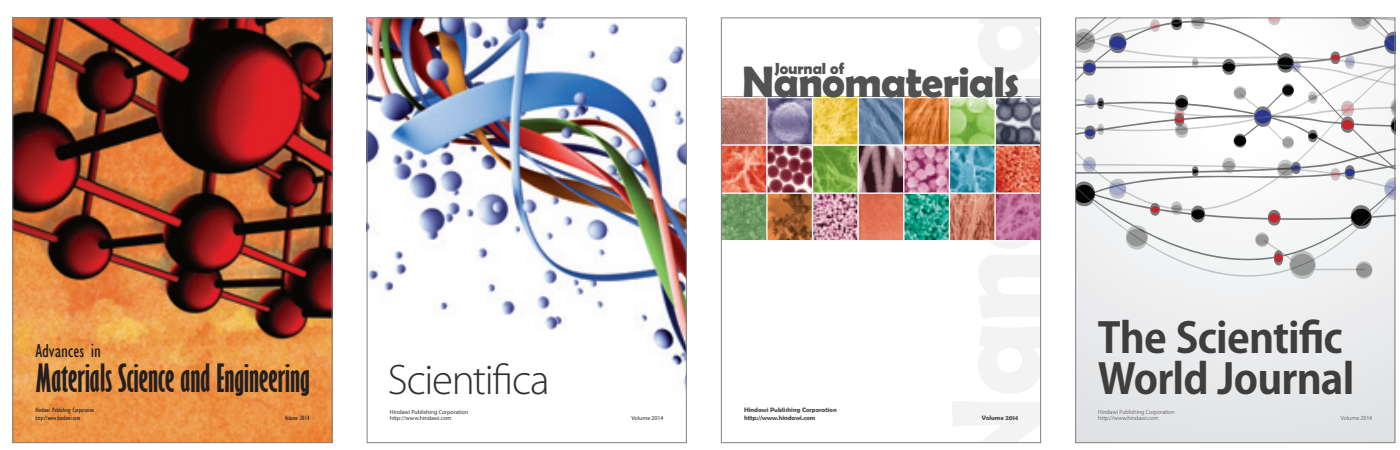

\section{The Scientific World Journal}
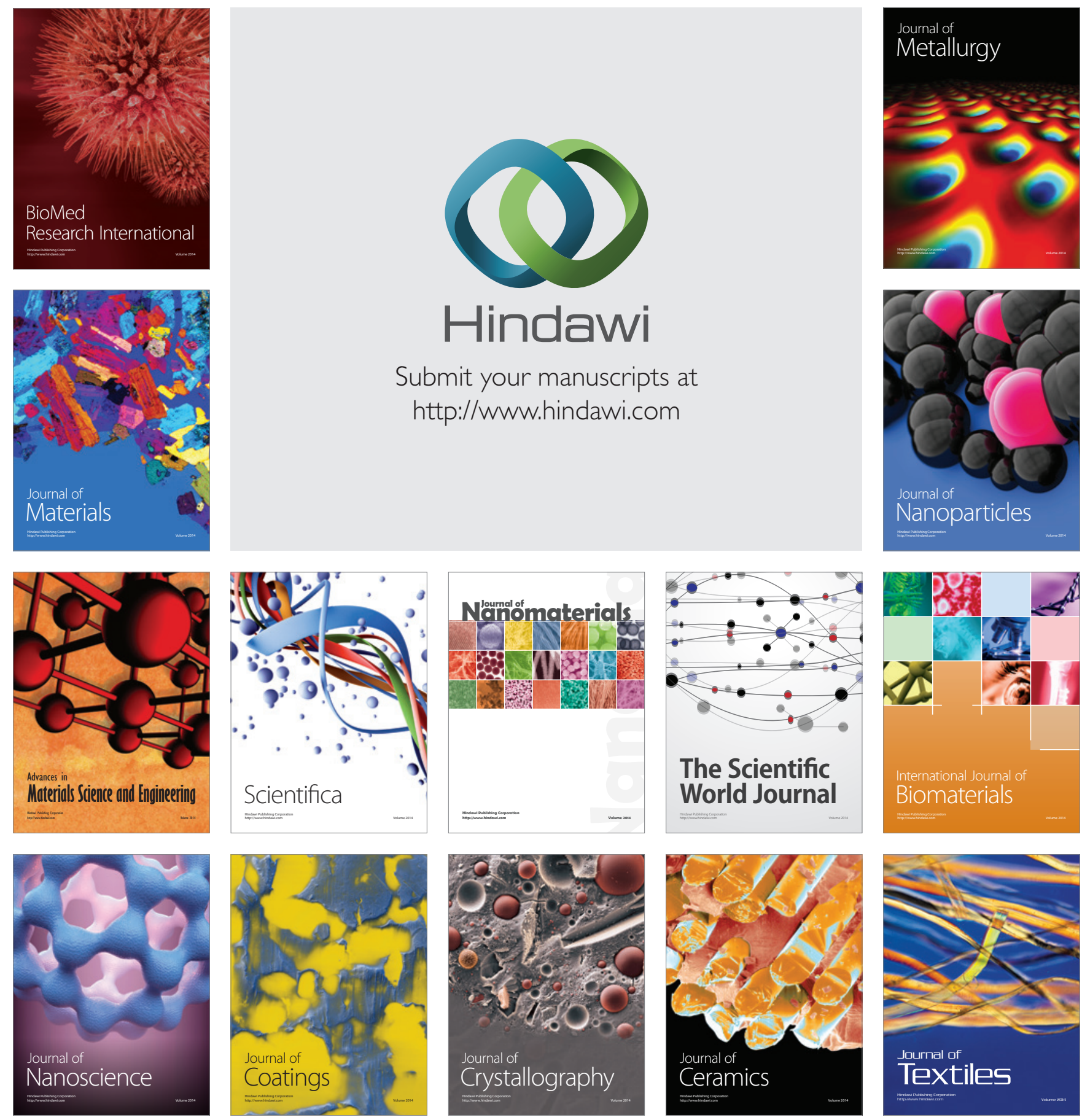